\title{
An Investigation of Errors in the Oral Performance of Advanced-level Iranian EFL Students
}

\author{
Alireza Hojati \\ Amin Higher Education Institution, Fouladshahr, Iran \\ E-mail: harries.alireza@gmail.com
}

\section{Doi: 10.5901/mjss.2013.v4n4p171}

\section{Abstract}

The skill of speaking in a non-native language has been the subject of many scholarly investigations and different aspects of it have been meticulously examined in recent decades. However, one dimension of this crucial foreign language skill, i.e. errors of advanced language learners, has apparently received less than adequate attention as the bulk of relevant research has focused almost exclusively on speaking errors of beginning-level and intermediate-level learners. To delve into this under-researched line of research, the researcher benefited from the oral performances of a group of twenty advanced-level Iranian students of English. The oral presentations of the participants were recorded and then grammatical, lexical and pronunciational errors featuring in them were identified, categorized and analyzed. The findings illustrate that, contrary to what might be assumed, advanced-level learners commit numerous errors in all the foregoing categories, especially in pronunciation and grammar. The findings, therefore, reveal the need for more scholarly research on linguistic errors of advanced-level EFL learners.

Keywords: Iranian EFL, Oral Errors, Advanced Learners

\section{Introduction}

\subsection{Overview}

Speaking, defined by Hinkel(2005) as "a process of oral language production", is one of the cardinal language skills traditionally referred to as the 'four skills'(2005). The skill of speaking in a non-native language, be it English or any other language, is arguably difficult to teach, master and assess(Cornfield(1966), Phillips(1993), CelceMurcia and Olshtain(2001), Espinosa(2003), Díaz-Rico(2008) ).

As linguistic research on second language acquisition has already revealed, there are fundamental differences between speaking one's mother tongue and speaking a non-native tongue. In this connection, Starr(1996) has commented : "all normal children learn to speak the mother tongue fluently, without benefit of formal schooling, text or classroom"(1996, p.7 ). Also, writing on the achievement of varying degrees of speaking proficiency in English as a non-native language, Richards and Renandya(2002) have pointed out that "it is difficult for EFL learners, especially adults, to speak the target language fluently and appropriately" (2002, p. 204).

\subsection{Related Literature}

As the available literature shows, learning to speak English as a non-native language is uniquely difficult, especially at the initial and intermediate stages of learning, and often leaves the learners with no option but to resort to code-switching, thinking-for-speaking patterns and other ways of maintaining and repairing their speech and preventing communication breakdowns(Robinson and Ellis(2008)).

The difficulties inherent in speaking a non-native language partly explain why most, if not all, learners deviate to varying degrees from what are regarded as norms of the target languages they speak. These deviations are referred to as 'errors'(Ellis(1994), Pienenamm \& KeBler (2011) ).

The study and analysis of learner errors has a rather long history dating back to the 1940s, when the so-called Contrastive Analysis Hypothesis $(\mathrm{CAH})$ rose to prominence in linguistics and, in its heyday, dramatically changed the way language learning was treated (Marmaridou, Nikiforidou \& Antonopoulou(2005)).

Today, the area of Error Analysis is not as promising and popular as it once was. 
However, it is still a significant area of study as well as an important and potentially revealing line of research in the realm of second/foreign language acquisition. As Nagaraj (1996) has indicated, errors are no longer treated as sinful entities. Rather, they are regarded as an ineluctable and systematic aspect of the complex process of language learning(1996).

Further, the examination and systematic classification and analysis of learner errors can have considerable benefits. Some of the most salient advantages of conducting Error Analysis include getting more information surrounding learners' internal constructs, allowing the observation of learner's language output, which paves the way for developing a better appreciation of processes involved in language learning, and providing researchers in the field with a framework for studying learner language(cited by Castillejos López1(2010)).

Keshavarz(2008), has touched upon a number of other benefits associated with the Error Analysis. He has asserted that learners, teachers and researchers can all be beneficiaries of the systematic analysis of learner errors. According to him, learners benefit from the errors they commit because they enable them to get feedback from the learning environment and subsequently make corrective changes to their hypotheses vis-à-vis the target language(2008, p.43).

Keshavarz has then cited Richards(1971)'s words to illustrate how teachers and researchers profit from learner errors. According to him, researchers in the field of psycholinguistics benefit from errors because they make it possible for psycholinguists to "examine the nature of the mental processes that seem to be involved in language(cited by Keshavarz(2008, p.45)). Furthermore, teachers are bound to derive benefits from their learners' errors because "by analyzing learners' errors, they would be able to discover their difficulties and devise a method for comparing them(cited by Keshavarz(2008), p.45)).

As has already been said, learner errors are both unavoidable and beneficial. One point regarding learner errors, around which this study revolves, is the frequency of their occurrence.

At the beginning and intermediate levels, the insufficiency of learners' lexico grammatical knowledge combined with many other factors can lead to the committing of numerous errors by the learners. This assumption has been referred to by Salgado(2011), who focused on and compared the number of errors committed by beginning-level, intermediate-level and advanced-level EFL students in the area of making requests, apologies and other pragmatic areas.

Although it may be assumed that the number of errors committed by the learners declines steeply, or almost disappears, as they go through more advanced stages of foreign language learning and boost their linguistic knowledge, there is evidence in the literature calling this assumption into question. Díaz-Rico(2008), for instance, has indicated that as learners become more proficient, the amount of language they produce increases and subsequently, the number of errors committed by them goes up as well. In a similar vein, Quintero, Inagaki and Kim(1998), who examined the number errors committed by third-year EFL students, have noted that more advanced students are likely to commit more errors than lower-proficiency students partly because they try to use complex grammatical structures and sophisticated vocabulary items in both speaking and writing more frequently. In line with what has already been said, a number of researchers have reported the committing of a fairly large number of errors by advanced-level non-native learners and students of English in both speaking and writing( Nehls(1991), Lafford and Salaberry (2003), Hudson and Brown(2001), Salgado(2011)).

A fairly large number of studies have already been conducted with the aim of indentifying, classifying, analyzing and interpreting some of the most common errors in the oral and written performance of Farsi-speaking Iranian EFL learners and students in Iranian EFL settings. Nezami and SadraieNajafi's 2012 study, which sought to detect and categorize high-frequency errors of a group of undergraduate Iranian EFL students, reveals that Farsi-speaking students/learners commit a sizeable number of errors in the area of grammar. The findings of their study illustrate that errors falling into categories of subject-verb agreement, prepositions, tenses, clauses, regularization, word order and articles all feature prominently in the performance of Iranian undergraduate students of English.

What this study's findings highlight is that the participants of low-, mid- and high-proficiency levels all committed a fairly large number of errors falling into the above-mentioned categories.

Another recent study, carried out by Abbasi and Karimnia(2011), has provided a list of commonlycommitted grammatical errors of both junior and senior undergraduate students in another Iranian university setting. The list includes errors which fall into categories of tenses, direct-indirect questions, quantifiers and intensifiers, prepositions, articles, use of Persian structures, subject-verb agreement, relative clauses and relative pronouns. 
Yet another recently-conducted study by Sadighi and Heydari(2012) has shown that, apart from grammatical errors, Iranian EFL learners commit a substantial number of lexical errors falling into the categories of synonymy, antonymy, hyponymy, repetition and collocations.

Although errors falling into the category of collocations have been reported by a number of researchers who studied Iranian EFL learners and students( Koosha \& Jafarpour(2006), Shokouhi \& Mirsalari(2010) ), errors falling into other categories have apparently received little attention by researchers. One of the few comprehensive taxonomies of lexical errors of EFL errors has been proposed by Hemchua and Schmitt(2006). Their taxonomy

features two cardinal categories, viz. 'formal errors' and 'semantic errors', each of which has many subcategories.

The category of 'formal errors' encompasses formal misselection, misformations and distortions. Formal misselection errors are divided into the sub-categories of suffix type, prefix type, vowel-based type, consonantbased type and false friends(2006).

Misformation errors are subdivided into borrowing L1 words, coinage and calque (2006). The category of distortions includes sub-categories of omission, overinclusion, misselection, misordering and blending(2006).

The second cardinal category, viz. semantic errors is sub-divided into four broad sub-categories, namely confusion of sense relations, collocational errors, connotation errors and stylistic errors(2006).

The sub-category of confusion of sense relations is further subdivided into four sub-categories of general term for specific term, overly specific term, inappropriate co-hyponyms and near synonyms(2006). The subcategory entitled collocational errors is further subdivided into four smaller categories of semantic word selection, statistically weighted preferences, arbitrary combinations and preposition partners (2006). Finally, the category of stylistic errors is subdivided into two smaller categories of verbosity and underspecification(2006).

Although the above-described taxonomy of lexical errors is, as indicated, a detailed one, few studies have been found to have focused on all of its lexical error categories. As indicated, most of the previous studies either have devoted the bulk of their focus to grammatical errors or have focused solely on lexical errors related to collocations. So, there are gaps in this area which require further attention.

In the area of pronunciation, there are appreciable differences between Farsi and English pronunciation systems from which many pronunciation-related problems and errors stem.

Swan and Smith(2001) have compiled a list of prominent pronunciation-related differences between the two languages in question. They have cited the non-occurrence of consonant clusters syllable-initially and syllablemedially in Farsi, differences between vowel sounds in Farsi and English, which can result in the confusion of many vowels and the ignoring of differences between them across the two languages in question, the unpredictability of stress-placement in Farsi, which does not exist in English, as well as intonation-related differences as the most notable pronunciation-associated and problematic dissimilarities between Farsi and English.

Seddighi(2010) has compiled another account of pronunciation-related difficulties confronting Farsi-speaking learners of English. Her account is based on the errors Farsi-speakers often commit thanks to differences between dissimilarities between their mother tongue and English(their target language). According to Seddighi's account, consonant clusters, past morpheme(ed), diphthongs, stress patterns, and intonation contours are among the most salient areas of difficulty for Farsi-speakers(2010).

Given the broadness of each of the above-mentioned areas of difference, two of them relevant to the current study ought to be given more attention here.

In the area of stress-placement, Swan and Smith(2001) have pointed out that, unlike English, Farsi word stress "is highly predictable, and generally falls on the final syllable of a word"(2001, p. 182). As a result, the authors have mentioned, Farsi-speaking learners of English are likely to experience big problems acquainting themselves with the rather chaotic and highly unpredictable stress patterns of the English language(2001).

With respect to consonant clusters, another prominent area of difference between English and Farsi pronunciation systems, Swan and Smith(2001) have noted that "consonant clusters do not occur within single syllables in Farsi, and Farsi speakers therefore tend to add a short vowel, either before or in the middle of the various English clusters"(2001, p. 181). The authors have also indicated that syllable-final and syllable-medial clusters of consonants are also likely to be problematical for Farsi speakers and, to tackle such problems, most Farsi-speakers tend to insert a short vowel sound between consonants(2001). 


\subsection{Rationale of the Study}

Given the unique and often long-lasting problems and challenges facing EFL learners and students on the one hand and the fact that errors, to a certain extent, reveal insightful information on the prominent and stubborn difficulties facing most learners on the other, this study aims to ascertain which types of lexical, grammatical and pronunciation-related errors are committed by a group of advanced-level post-graduate Iranian EFL students during their oral presentations and what frequencies they have. Further, it aims to highlight and qualitatively analyze high-frequency errors of the students by invoking the existing literature on contrastive linguistics.

\subsection{Research Questions}

Having gone through the already available literature on Error Analysis, contrastive linguistics and Iranian EFL speaking, the researcher formulated the three research questions below:

1. What are the frequently-committed errors in the oral performance of the participants?

2. What are the most frequently-committed errors of the participants in categories of vocabulary, grammar and pronunciation?

3. How can the high-frequency errors of the participants be interpreted and qualitatively explained?

\section{Methodology}

\subsection{Participants}

Twenty post-graduate EFL students specializing in TEFL(Teaching English as a Foreign Language) and Translation Studies were included in the study. Thirteen out of the twenty participants were females between the ages of 24 and 34 and seven participants were males aged between 25 and 31. All the participants were affiliated with Sheikhbahaee University, a small non-governmental non-profit university located near the metropolis of Isfahan in central Iran. All the participants were in the last stage of their post-graduate studies during which they were required to orally present and defend their M.A. dissertations in order to be awarded their degrees.

\subsection{Materials}

The materials used in the current study consisted of 20 recorded oral presentations given by the participants in their respective thesis thesis defence sessions as well as the ensuing interactions they had with internal and external examiners of their theses. Ten of the defence sessions were held between Shahrivar $24^{\text {th }}$ and Mehr $30^{\text {th }}, 1390$ and another ten sessions were held between Bahman $11^{\text {th }}$ and Esfand $4^{\text {th }} 1390$. All the oral materials collected for this research were recorded using a recording device without the knowledge of participants and examiners of their dissertations.

\subsection{Procedures}

The researcher attended all the twenty thesis defence sessions in person and used a small recording device to record and document all the oral materials relevant to his research.

After each defence session, all the relevant interactions were carefully listened to four times and errors detected in them were classified into three categories, namely 'lexical', 'grammatical' and 'pronunciation-related'. To make sure that what he had identified as 'error' was indeed an error, the researcher used the Oxford Advanced Learner's Dictionary and two grammar books, viz. English Grammar Digest and Communicate What You Mean, as credible references for checking each and every entity identified as an error. In the case of more problematical cases in which it was nigh on impossible for him to determine if some presumed errors were indeed errors, the researcher consulted two associate professors of Sheikhbahaee University both of whom had more than three decades of experience.

After the completion of data-collection, error-classification and frequency-computation activities, the researcher embarked upon the qualitative analysis of the obtained data using highlights of the already-existing literature on each error's possible cause/s andimplications. 


\section{Results}

The following tables summarize the findings which data-analysis procedures have yielded.

\begin{tabular}{|l|c|}
\hline Category of Errors & Frequency of Errors \\
\hline Grammar & 51 \\
\hline Vocabulary & 32 \\
\hline Pronunciation & 61 \\
\hline
\end{tabular}

Table(1). Total number of errors committed by study's participants

\begin{tabular}{|l|l|}
\hline Grammatical Errors & Frequencies \\
\hline Articles & 12 \\
\hline Prepositions & 8 \\
\hline Clauses & 11 \\
\hline Relative Pronouns & 7 \\
\hline Subject-verb Agreement & 3 \\
\hline Conditionals & 7 \\
\hline Countable/Uncountable Nouns & 3 \\
\hline
\end{tabular}

Table(2). Frequencies of participants' grammatical errors in seven different categories

\begin{tabular}{|l|l|}
\hline Prefix/Suffix & 5 \\
\hline Sense Relations & 5 \\
\hline Cognates & 2 \\
\hline Collocations & 6 \\
\hline Misselection of words & 8 \\
\hline Near Synonyms & 6 \\
\hline
\end{tabular}

Table(3). Frequencies of participant's lexical errors in six different categories

\begin{tabular}{|l|l|}
\hline Insertion of vowels & 5 \\
\hline Stress placement & 18 \\
\hline Wrong pronunciation of sounds & 28 \\
\hline Intonation contours & 10 \\
\hline
\end{tabular}

Table(4). Frequencies of participants' pronunciation-related errors in four different categories

\section{Discussion and Conclusions}

At the beginning of this section, three research questions which the study attempts to find answers to ought to be reiterated;

1. What are the most frequently-committed errors in the oral performance of the participants?

2. What are the most frequently-committed errors of the participants in categories of vocabulary, grammar and pronunciation?

3. How can the high-frequency errors of the participants be interpreted and qualitatively explained? 
With respect to the first two research questions, as tables(1), (2) and (4) indicate, pronunciation-associated errors had the highest frequency(61), followed by grammar-related errors(51). So, the study's participants made more pronunciation-related and grammatical errors than lexical errors.

To get a more detailed picture of high-frequency errors, each error category and its subdivisions need to be considered severally.

In the error category of grammar, as table(2) shows, errors in the use of articles had the highest frequency(12), and errors in the use of clauses and prepositions had the second and third highest frequencies of grammatical errors(11 and 8 respectively).

In the category of lexical errors, as figures presented in table(3) illustrate, errors made in the choice of the proper lexical items by participants had the highest frequency(8), and errors in the areas of near synonyms and collocations had the second highest frequency of lexical errors.

With regard to the error category of pronunciation, as table(4) indicates, errors associated with the wrong pronunciation of individual words were made more frequently than other errors in the same error category. Further, errors in the placement of word stress constitute the second high-frequency sub-category of pronunciation-linked errors which the study's participants committed during their oral presentations.

As with the third research questions, some relevant highlights of the current literature as well as the study's results need to be examined.

In the area of grammar, as stated earlier, errors in the use of articles, clauses and prepositions had the highest frequencies respectively. To partially account for the high frequency of the occurrence of errors falling into the above-mentioned grammatical categories, a number of points in the literature must be noted.

The first point is that although Farsi is not an article-less language, its articles, as Swan and Smith(2001) have pointed out, are radically different from English articles. Besides, English definite and indefinite articles do not have any Farsi equivalents, which makes the acquisition of English articles even more problematical for Farsi-speakers(2001).

The second point is that English prepositions are particularly complex and problematical for foreign learners in general. One reason accounting for this point is that prepositions have many different meanings and uses in different contexts (Mana \& University of California, Los Angeles(2007) ). Another reason is that although learners have prepositions in their own mother tongues and have an understanding of them, notable differences can be observed between prepositions used in different languages. Writing on this point and its pedagogical implications, Satya(2008) has commented: "English prepositions are a problem because different languages use different prepositions to express the same ideas"( 2008 , p. 26).

Another reason is that, generally speaking, prepositions of one language rarely have precise counterparts or equivalents in other languages and English prepositions are no exception(Erwin, (2004) ). Moseley(1996), writing on the acquisition of colloquial Latvian by English-speakers, has echoed the same point: "Latvian prepositions do not have exact equivalents in English"(1996, p.41 ). Yet another reason, which is directly related to Farsi-speaking learners has been touched upon by Swan and Smith(2001): "In Farsi, prepositions are frequently used after verbs, but often they are different from the ones used in English. Farsi speakers tend to translate the prepositions directly into English(p. 189). Mahmoodzadeh(2012), who conducted a cross-linguistic study of English and Farsi prepositions and Farsi-speakers' errors associated with them, has also provided a research-based explanation as to why English-prepositions are difficult for learners. According to him, the high level of unpredictability of English prepositions as well as the flexibility with which different combinations can be made by using them contribute to the unique problematical nature of English prepositions for speakers of other languages, including Farsi speakers.

The third point which must be noted in order to partly explain the high-frequency of grammar errors, is related to complex structures known as 'clauses'. As Murray(2012) has indicated, English clauses, like many other complex grammatical constructions, are rather difficult for learners from different linguistic backgrounds. However, one type of English clauses known as 'relative clauses' can be much more difficult for foreign learners, including Farsi-speakers, than other clause types. In fact, some research findings have revealed that speakers of some languages including Arabic and Farsi are more likely to fail to acquire and accurately use English relative clauses(cited in Savard \& Laforge (1981), Liceras(1986), Gass \& Selinker(1992), Gass(2008).

Part of the reason for the well-documented point that Farsi-speakers face more problems with and commit more errors in using English relative clauses is that, as Swan and Smith(2001) have explained, there is just one relative pronoun in Farsi. This pronoun is used to refer not only to humans, but also to animals, objects and other entities(2001). 
Making the issue further complicated is the fact that the sole Farsi relative pronoun is also used "when the pronoun is the subject or the object of the verb, or when a possessive is required(Swan and Smith(2001), p. 190) ). As a result, the authors have concluded, selecting the appropriate English relative pronoun can be difficult for Farsi learners(2001).

Another source of Farsi-speakers' difficulty with English relative clauses is that, in English, unlike Farsi, the object pronoun of a relative clause is omitted(Swan and Smith(2001). The tendency of many Farsi-speaking learners not to omit the object pronoun of English relative clauses they use leads to the committing of frequent errors by them in this sub-category of grammatical errors.

Taking the above-mentioned points relating to grammatical areas of articles, prepositions and clauses, it can be said that most of the errors committed by the study's participants can be partly attributed to the influence of their mother tongue, i.e. Farsi, on their speaking in English. This hold particularly true for persistent errors in the use of relative clauses as well as for their omission and redundant use of English articles in their oral performance. With respect to the area of preposition, however, L1 influence can be cited as only one factor out of many factors contributing to difficulties for the study's participants. As stated earlier, English prepositions carry multiple different meanings and can be flexibly used in a wide variety of combinations. Therefore, part of the participants' difficulties resulting in errors can be attributed to the intra-lingual problems which they encountered during their oral performance.

Regarding the high-frequency errors falling into three sub-categories of lexical errors, namely 'misselection of words', 'collocations' and 'near synonyms', two points have to be mentioned here.

The first point is that, as experts in the area of translation was pointed out time and again, complete synonymy does not exist between languages(cited in Stede(1999), Clements(2006), Shiyab(2006)). Writing on this issue, Schmitt(2000) has noted that there are semantic boundaries, even between the words regarded as synonyms. Traxler (2011) has pointed out that the failure to pay attention to lexical word boundaries, specially with respect to synonyms and near-synonyms, is one major cause of lexical errors committed by learners. To further explain semantic lexical errors, Traxler has referred to one type of lexical errors called "semantic substitution error", which arises thanks to the disregarding of the semantic boundaries between words with similar meanings(2011). Semantic substitution errors, which constitute a large proportion of learner errors((Altmann(1998), Hartsuiker(2005), Agustín Llach (2011) ) often involve the use of the so-called 'semi-synonyms' or words with close meaning(2011).

The second point is related to English collocations, words which routinely keep each other's company. As Armstrong and Armstrong(1994) have noted, collocations are by and large difficult for foreign learners of English to learn. Echoing the same point, Neves Seesink and West Virginia Univeristy(2007) have called the attention of language educators to the problematical nature of English collocations for learners. They have indicated that one reason making collocations difficult is that there are, apparently, no obvious logical or guessable relationship between words which collocate with each other. In order words, there is no specific or hard and fast rule governing the combining of words to form collocations. Another reason which Neves Seesink and West Virginia

Univeristy have touched upon is that the number of collocations is just too many, making it very difficult, if not impossible, to memorize and easily remember many such word combinations(2007). Yet another reason, which Koosha and Zarei(2002) have referred to is the use of diverse prepositions in most collocations. As noted previously, prepositions themselves pose numerous problems for learners. When they are used in collocations without being governed by any specific rule, they can make collocations even more complicated for learners(Koosha \& Zarei(2002), cited in Koosha \& Jafarpour(2006) ).

Taking the above-presented points into account, it can be stated that a large proportion of lexical errors committed by the current study's participants are partly attributable to their failure to select appropriate words, synonyms and others, which is illustrative of their difficulties in appreciating semantic boundaries between words with close meanings. With respect to the error category of pronunciation, as pointed out in the Review of Literature section of the paper, English and Farsi pronunciation systems are wildly different to each other in many respects not least word stress, intonation, consonant clustering and the relationship between spelling and pronunciation of many words. As indicated earlier, Swan and Smith(2001) have provided a comprehensive and detailed account of the foregoing differences and many other differences in their seminal book entitled 'Learner English A teacher's guide to interference and other problems'. From among Iranian scholars and researchers, Yarmohammadi(2005) has conducted extensive research on the area of pronunciation and has referred to a number of tricky areas of pronunciation with Iranian EFL learners can face considerable problems with. 
According to Yarmohammadi's account, word stress, sentence accent, emphatic stress and consonant clusters feature prominently in pronunciation errors of Iranian EFL learners(2005).

Echoing the fact that Farsi word stress is far less messy than English word stress, Yarmohammadi has pointed out that, generally speaking, Farsi word stress falls on the last syllable(2001, p. 77). However, compared with Farsi, "the degree of predictability of word stress is very low in English"(2001, p. 87).

Taking the foregoing differences, especially those relating to word stress and consonant clustering, into account, it can be said that a fairly large proportion of pronunciation errors committed by this study's participants can be partially explained by invoking the existence of appreciable differences between their L1(Farsi) and their target language (English).

One thing, which requires further explanation in the area of pronunciation errors is that, as table(4) of the 'Results' section shows, participant's errors in the pronunciation of individual sounds had the highest frequency of pronunciation-linked errors. This sobering point, which took the researcher by surprise and for which no specific point has been found in the existing literature, calls for further research. However, the researcher's somewhat subjective explanation for this is that, given the limited exposure of the participants to authentic English materials through audio-visual sources, which effectively deprived them of opportunities for improving their pronunciation or keeping it at an adequate level through repeated exposure to the correct pronunciation of words, they committed many errors in the pronunciation of sounds corresponding to words with which they were well familiar. Further, the researcher's view is that, given the repeated failure of some of the study's participants in correctly pronouncing some sounds in familiar and frequently-used words such as 'determine'( which was pronounced /ditermain/), and 'analytical'( which was pronounced /aenelaitikal/), the failure of teachers and peers to provide corrective feedback has perhaps led to the fossilization and solidification of such errors, something deserving of more attention and scholarly research.

\section{Implications of the Study}

This study spotlights some of the major linguistic problems with which advanced-level Iranian EFL students have to grapple, especially the ones corresponding to grammar and pronunciation. So, Iranian EFL educators at the tertiary level as well as instructors teaching English at the advanced level in Iranian language schools and institutes can benefit from the findings of this study. One of major implication of the study is that it should not be assumed that advanced EFL students don't have any major problem with English pronunciation and grammar, two of the most difficult areas of English, and more scholarly and research attention ought to be devoted to the further examination, analysis and alleviation of such problems which manifest themselves as errors in the students'/ learners' speaking.

\section{References}

Abbasi, M, Karimnia, A. (2011). An analysis of grammatical errors among Iranian translation students: Insights from interlanguage theory. Retrieved from www.europeanjournalofsocialsciences.com/.../EJSS 25 4 07.pdf. on October 3th, 2012.

Agustín Llach, M. (2011). Lexical Errors and Accuracy in Foreign Language Writing. Great Britain: Multilingual Matters.

Altmann, G. (1995). Cognitive Models of Speech Processing: Psycholinguistic and Computational Perspectives. Massachusetts: MIT Press.

Armstrong, A., Armstrong, S. (1994). Using Large Corpora. The United States of America: MIT Press.

Celce-Murcia, M. , Olshtain. E. (2001). Discourse and Context in Language Teaching: A Guide for Language Teachers. The United States of America: Cambridge University Press.

Clements, J. (2006). History, Society And Variation: In Honor of Albert Valdman. Philadelphia: John Benjamins Publishing

Cornfield, R. (1966). Foreign language instruction: dimensions and horizons. New York: Ardent Media.

Diaz-Rico, L. (2008). A course for teaching English learners. The United States of America: The University of Michigan.

Ellis, R. (1994). The Study of Second Language Acquisition. The United Kingdom: Oxford University Press.

Erwin, W. (2004). A Short Reference Grammar of Iraqi Arabic. The United States of America: Georgetown University Press.

Gass, S. (2008). Second Language Acqusition: An Introductory Course. New York: Taylor \& Francis.

Gass, S., Srlinker, L. (Editors). (1992). Language Transfer in Language Learning. The United States of America: John Benjamins Publishing.

Hartsuiker, R. (2005). Phonological Encoding and Monitoring in Normal and Pathological_Speech. The United States of America: Psychology Press.

Hemchua, S., Schmitt, N. (2012). An analysis of lexical errors in the English compositions of Thai learners. Mediterranean Journal of Social Sciences Vol. 3 (2) May 2012, pp.1-25. 
Hinkel, E. (2005). Handbook of Research in Second Language Teaching and Learning. New York: Taylor \& Francis.

Hudon, T., Brown, J.(editors). (2001). A Focus on Language Test Development: Expanding the Language Proficiency Construct Across a Variety of Tests. The United States of America: Natl Foreign Lg Resource Ctr.

Keshavarz, M. (2008). Contrastive Analysis and Error Analysis. Tehran: Rahnama Press.

Koosha, M. , Jafarpour, A. (2006). Data-driven Learning and Teaching collocation of prepositions: The Case of Iranian EFL Adult Learners. Asian EFL Journal: Volume 8. Issue 8, Article 2.

Lafford, B., Salaberry, M. (2003). Spanish Second Language Acquisition: State of the Science. The United States of America: Georgetown University Press.,

Liceras, J. (1986). Linguistic theory and second language acquisition: the Spanish nonnative grammar of English speakers. California: the University of California.

López1, W. (2010). Error Analysis In A Le Armstrong, A., Armstrong, S. (1994). Using Large Corpora. The United States of America: MIT Press.

Mahmoodzadeh, M. (2012). A Cross-linguistic Study of Prepositions in Persian and English: The Effect of Transfer. Theory and Practice in Language Studies, Vol. 2, No. 4, pp. 734-740, April 2012. www.academypublisher.com/tpls/vol02/no04/tpls0204.pdf.

Mana, M. (2007). "Informative Assessment": Investigations of Teachers' Written Feedback with Middle School English Language Learners. Los Angeles: ProQuest.

Marmaridou, S., Nikiforidou, K., Antonopoulou, E. (2005). Reviewing Linguistic Thought: Converging Trends for the 21st Century. Berlin: Walter de Gruyter.

Moseley, C. (1996). Colloquial Latvian: The Complete Course for Beginners. New York: Routledge.

Murray, N. (2012). Writing Essays in English Language and Linguistics: Principles, Tips and Strategies for Undergraduates. New York: Cambridge University Press.

Nagaraj. (1996). English Language Teaching: Approaches, Methods, Techniques. India: Orient Blackswan.

Nehls, D.(Editor). (1991). Studies in contrastive linguistics and error analysis: Practical applications. The United States of America: the University of California.

Nezami, A., Najafi, M. (2012). Common Error Types of Iranian Learners of English. ournal of English Language Teaching Vol. 5, No. 3; March 2012. Retrieved from ccsenet.org/journal/index.php/elt/article/view/15276. On October 1th, 2012.

Phillips, S. (1993). Young Learners. Oxford: Oxford University Press.

Pienemann, M, \& KeBler, J. (2011). Studying Processability Theory: An Introductory Textbook. The United States of America: John Benjamins Publishing.

Quintero, K., Inagaki, S., Kim, H. (1998). Second Language Development in Writing: Measures of Fluency, Accuracy, \& Complexity. Natl Foreign Lg Resource Ctr.

Richards, J \& Renandya, W. (2002). Methodology in Language Teaching: An Anthology of Current Practice. The United States of America: Cambridge University Press.,

Robinson, P, Ellis, N. (2008). Handbook of Cognitive Linguistics and Second Language Acquisition. New York: Taylor \& Francis.

SadighiF., Heydari, P. (2012). Cohesion Analysis of L2 Writing: The Case of Iranian Undergraduate EFL Learners. Mediterranean Journal of Social Sciences Vol. 3, No. 2, May 2012.

Salgado, E. (2011). The Pragmatics of Requests and Apologies: Developmental Patterns of Mexican Students. Philadelphia: John Benjamins Publishing.

Satya, R. (2008). Modern Methods of Teaching English. New Delhi: APH Publishing.

Savard, J. , Laforge, L. (1981). Actes Du 5e Congrès de: Montréal, Août. Montral: Presses Université Laval.

Schmitt, N. (2000). Vocabulary in Language Teaching. New York: Cambridge University Press.

Seddighi, S. (2010). An_Account_of_Iranian_EFL_Pronunciation_Errors through L1 Transfer. Iranian_Journal_of_Applied_ Language_Studies,_Vol_2,_No_2,_2010, Retrieved on October 5 $5^{\text {th }}, 2012$.

Semel, E., Ronser, S. (2011). Understanding Williams Syndrome: Behavioral Patterns and Interventions. New Jersey: New York: Taylor \& Francis

Shiyab, S. (2006). A Textbook of Translation: theoretical and practical implications. London: Garant.

Shokouhi, H., Mirsalari, G. (2010). Collocational Knowledge versus General Linguistic Knowledge among Iranian EFL Learners. TESLEJ(The Electronic Journal for English as a Second Language): March 2010 - Volume 13, Number 4.

Starr, W.(1996). The Suzuki violinist: a guide for teachers and parents. The United States of America: Alfred Music Publishing.

Stede, M. (1999). Lexical Semantics and Knowledge Representation in Multilingual Text Generation. Massachusetts: Springer.

Swan, M. Smith, B. (2001). Learner English: A Teacher's Guide to Interference and other Problems, Volume 1. The United States of America: Cambridge University Press.

Tokuhama-Espinosa, T. (2003). The multilingual mind: issues discussed by, for, and about people living with many languages. The United States of America: Praeger.

Traxler, M. (2011). Introduction to Psycholinguistics: Understanding Language Science. The United States of America: John Wiley \& Sons.

Yarmohammadi, L. (2005). A Contrastive Phonological Analysis of English and Persian: A Course Book in Applied Phonological Studies. Shiraz: Shiraz University Press. 
